\title{
Can monolinguals be like bilinguals? Evidence from dialect switching
}

Neil W. Kirk, Vera Kempe, Kenneth Scott-Brown, Andrea Philipp and Mathieu Declerck

This is the accepted manuscript (C) 2017, Elsevier Licensed under the Creative Commons AttributionNonCommercial-NoDerivatives 4.0 International (CC BY-NC-ND 4.0)

http://creativecommons.org/licenses/by-nc-nd/4.0/

\section{(cc) EY-NC-ND}

The published article is available from doi:

http://dx.doi.org/10.1016/j.cognition.2017.10.001 
Can monolinguals be like bilinguals? Evidence from dialect switching.

\author{
Neil W. Kirk ${ }^{1}$ \\ Vera Kempe ${ }^{1}$ \\ Kenneth Scott-Brown ${ }^{1}$ \\ Andrea Philipp ${ }^{2}$ \\ Mathieu Declerck ${ }^{3}$
}

${ }^{1}$ Abertay University, Dundee, Scotland, United Kingdom

${ }^{2}$ Institute of Psychology, RWTH Aachen University, Aachen, Germany

${ }^{3}$ Laboratoire de Psychologie Cognitive,

Aix-Marseille University and Centre de la Recherche Scientifique, Marseille, France

Running Head: Dialect Switching

Keywords: dialect, language switching, bilingualism,

Acknowledgements: This research was funded by Leverhulme Trust Grant RPG-375. Correspondence concerning this article should be addressed to Vera Kempe, Division of Psychology, Abertay University, Dundee DD1 1HG, Scotland, U. K. 


\begin{abstract}
(150 words)
Bilinguals rely on cognitive control mechanisms like selective activation and inhibition of lexical entries to prevent intrusions from the non-target language. We present cross-linguistic evidence that these mechanisms also operate in bidialectals. Thirty-two native German speakers who sometimes use the Öcher Platt dialect, and thirty-two native English speakers who sometimes use the Dundonian Scots dialect completed a dialect-switching task. Naming latencies were higher for switch than for non-switch trials, and lower for cognate compared to non-cognate nouns. Switch costs were symmetrical, regardless of whether participants actively used the dialect or not. In contrast, sixteen monodialectal English speakers, who performed the dialectswitching task after being trained on the Dundonian words, showed asymmetrical switch costs with longer latencies when switching back into Standard English. These results are reminiscent of findings for balanced vs. unbalanced bilinguals, and suggest that monolingual dialect speakers can recruit control mechanisms in similar ways as bilinguals.
\end{abstract}


Models of bilingual word production assume shared conceptual yet distinct languagespecific lexical representations. For example, when wishing to express the concept 'DOG', English-German bilingual speakers have both the English lexical entry 'dog' and the German lexical entry 'Hund' at their disposal, and have to select one of them depending on the target language. A variety of experimental paradigms (e.g. Blumenfeld \& Marian, 2011; Dimitropoulou, Duñabeitia \& Carreiras, 2011; Hermans, Bongaerts, de Boot \& Schreuder, 1998) have demonstrated that bilingual lexical access during comprehension and production is liable to cross-language influence. Two lines of evidence have specifically demonstrated the consequences of crosslanguage influence in word production: First, when cued to switch between languages during word production, bilinguals exhibit a language switch cost: they take longer to produce a word in one language after just having produced a word in the other language, compared to trials where the preceding word was produced in the same language (e.g. Meuter \& Allport, 1999). Second, cognates, i.e. etymologically related words which have considerable phonological/orthographic overlap with their translation equivalent in the other language, are named faster than non-cognates (Costa, Caramazza \& Sebastian-Galles, 2000).

As we will briefly discuss below, most bilingual word production models explain these findings based on the assumption that the bilingual lexicon contains distinct and separate lexical entries for each language, and that these entries are in some way tagged for language membership (but see Shook \& Marian, 2013). This is in contrast to monolingual models of word production which instantiate a single lexical entry for each concept. However, in many situations monolinguals encounter considerable socio-linguistic variation through exposure to different varieties such as dialects, accents, sociolects or speech registers (e.g. Foulkes \& Hay, 2015), and are able to flexibly switch between these varieties depending on the social context of the communicative situation. Although the question of whether two varieties constitute different languages vs. different dialects, or different dialects vs. different accents is a notoriously controversial one, there is agreement that dialects of a language are characterised by a considerable degree of lexical overlap that results in mutual intelligibility. Yet quite often individuals who are functionally bidialectal are identified as monolinguals by instruments that rely on self-report of linguistic knowledge, e.g. the widely used Language Experience and Proficiency Questionnaire (LEAP-Q; Marian, Blumenfeld \& Kaushanskaya, 2007), simply because those instruments do not include questions about non-standard variants of the respondents' native languages. It is possible that flexible use of various socio-linguistic varieties such as dialects relies on mechanisms that are similar to the ones that underpin lexical access in bilinguals. If that is the case then strong qualitative distinctions between monolingual and bilingual models of word production seem unwarranted, as bilinguals and bidialectal monolinguals might, in fact, not be fundamentally different in terms of the architecture of their lexicon and the mechanisms that underlie lexical access. To address this question, we asked in this study whether bidialectal monolingual speakers, who use an urban dialect of their native language, display language switch costs and cognate facilitation effects that are similar to the ones observed in bilinguals.

\section{Language switch costs:}

One prominent method of studying bilingual lexical access during word production involves cueing bilingual participants to name digits or pictures in one or the other language. This language-switching task has been adapted from non-linguistic task- 
switching research (for a review, see Kiesel et al., 2010). Results typically show a cost associated with switching languages compared to producing words in the same language as in the previous trial; in unbalanced bilinguals, this cost tends to be greater when switching back into the more dominant language (e.g. Macizo, Bajo \& Paolieri, 2012; Meuter \& Allport, 1999; Philipp, Gade \& Koch, 2007) while for balanced bilinguals, switch costs tend to be symmetrical across languages (Costa \& Santesteban, 2004; Costa, Santesteban \& Ivanova, 2006). Language switching costs arise either through inhibition or through selective activation (for a recent review, see Declerck \& Philipp, 2015a). For example, one influential model, the Inhibitory Control Model (Green, 1998; Abutalebi \& Green, 2008), postulates that entries in the bilingual lexicon are tagged as belonging to one or the other language, and that in order to exercise language control and to prevent intrusions from the non-target language, the language schema encompassing all entries belonging to the non-target language needs to be inhibited while the target language schema remains active so that the associated lexical entries can be selected. Bilinguals who are highly proficient in both languages display symmetrical switch costs because the required levels of inhibition are proportional to the strengths of the representation of each language (Bobb \& Wodniecka, 2013). Unbalanced bilinguals, on the other hand, display asymmetrical switch costs involving longer latencies when switching into the L1, a paradoxical finding that is assumed to reflect task set inertia because it takes longer to overcome the stronger inhibition that was required to block out the dominant language on previous trials.

An alternative account, the language-specific selection hypothesis (e.g. Costa \& Caramazza, 1999; Costa \& Santesteban, 2004; Roelofs, 1992), suggests that inhibition is not required to prevent non-target language intrusions, and that lexical selection operates only over those entries that belong to the target language. According to this account, selection thresholds can be set differently for each language enabling bilinguals to prioritise access to one or the other language without the need for inhibition (Poulisse, 1997; Costa et al., 2006; but see Declerck, Thoma, Koch \& Philipp, 2015). Under this account, language-specific selection occurs when lexical representations have been integrated into the lexicon and tagged according to language membership. Only when lexical representations are sufficiently novel will it prove necessary to inhibit the stronger language in order to produce words with relatively sparse lexical representations (Costa et al., 2006).

Regardless of whether the proposed mechanism that ensures language control is inhibition or selective activation, most models assume that language selection operates on the lexical level (but see La Heij, 2005, for a proposal of language selection on the conceptual level; and Declerck \& Philipp, 2015a; Gollan, Schotter, Gomez, Murillo, \& Rayner, 2014 for a proposal of language control at the phonological level). In these models, lexical entries are either tagged individually for language membership or connected to language nodes (Dijkstra \& Van Heuven, 2002), to allow for the activation of language schemas that regulate competition between the lexical entries associated with the different languages. The question we are asking here is whether we can observe similar competition effects for lexical entries that belong to different socio-linguistic varieties. How do individuals who frequently switch between the standard language and a local dialect perform contextappropriate lexical selection? To tackle this question we examine whether bidialectal speakers display a similar pattern of switch costs as bilinguals.

\section{Cognate facilitation effects:}


Another prominent effect that provides insight into the structure of the bilingual lexicon is the cognate facilitation effect. Studies of bilingual lexical access have demonstrated facilitatory effects for interlingual cognates resulting in faster naming latencies for words that share phonological or orthographical features. Again, several proposals can account for this effect (see Costa, Santesteban \& Caño, 2005): One possibility is a cascading mechanism whereby cognates activate the lexical representation of their translation equivalent in the non-target language, and both entries then jointly activate the shared elements of their phonological form resulting in its greater activation compared to non-cognates who do not receive this additional activation (Costa et al., 2000). Another possibility is that activation on the segmental level is propagated back thereby activating both the target lexical entry as well as it's translation equivalent, and both of these representations iteratively activate the segmental level thereby facilitating cognate production through an interactive process (Bernolet, Hartsuiker, \& Pickering, 2012). While it is beyond the scope of this study to adjudicate between these different studies, we simply note that both models presume language-specific lexical entries in the bilingual lexicon.

Recent studies have also described interesting interactions between the phonological overlap found in cognates and performance in the switching task: When cognates and non-cognates are presented in separate blocks, switch costs are smaller for cognates (Declerck, Koch \& Philipp, 2012), due to facilitation arising from the phonological co-activation of the non-target language cognates (Declerck \& Philipp, 2015a). However, when cognates and non-cognates are mixed, switch costs in general, and the switch cost asymmetry in particular, tend to be larger for cognates (Christoffels, Firk \& Schiller, 2007; Filippi et al., 2014), although the specific locus of the inhibitory effect in this experimental set-up is not entirely clear. In the present study, we will therefore investigate language control during bidialectal picture naming for cognates and non-cognates presented in separate blocks. If both varieties are simultaneously active in bidialectals, we predict a general cognate facilitation effect as well as a reduction in switch costs for cognates.

\section{Bilingualism vs. bidialectism:}

To investigate whether bidialectal monolinguals rely on the same underlying mechanisms of lexical access as bilinguals, we tested two types of bidialectal speakers - native German speakers residing in the Aachen area who, in addition to Standard German, spoke a local Low German dialect called Öcher Platt, and native English speakers residing in the Dundee area who, in addition to Standard English, spoke a local variety of the Lowland Scots dialect called Dundonian. Testing two different types of bidialectals with different native languages allows us to see whether the obtained results can be generalised cross-linguistically.

Our study is not the first to investigate lexical access in closely related varieties. Costa and colleagues (Costa \& Santesteban, 2004, Costa et al., 2000; 2006) have investigated highly proficient bilinguals of two typologically related languages, Spanish and Catalan, and found symmetrical switching costs as well as cognate facilitation effects. Although Catalan has an $85 \%$ degree of lexical overlap with Spanish according to the estimate provided in the Ethnologue database (Lewis, Simons \& Fenning, 2016), which is at the threshold of what is considered mutually intelligible, its status differs considerably from that of the dialects that we investigate here. First, Catalan has the status of an official language in Andorra, Catalunia, and 
the Balearic Islands and is a recognised minority language in several other regions. Secondly, it has a standardised orthography and an extensive written literature. Thirdly, most bilingual speakers will have received some degree of schooling in Catalan. Finally, despite the large degree of lexical similarity to Spanish, which led to its temporary classification as a Spanish dialect during certain historical periods, its phonological, lexical and morpho-syntactic features place it closer to other languages like Occitan and French (Feldhausen, 2010). As a result, speakers of Spanish and Catalan will consistently self-identify as bilinguals in language background questionnaires.

In contrast, the two dialects investigated here exist only as low varieties in diglossic situations, i.e. situations in which the same speakers use different varieties of a language depending on social and situational context. In general, in diglossic situations two varieties tend to differ in social prestige, which has led to the distinction between high (prestigious) and low (less prestigious) varieties (Ferguson, 1959). It is characteristic for such diglossic situations that the social contexts in which either variety is being used are clearly separated and mixing of varieties would in most cases be considered socially inappropriate (Ferguson, 1959). Diglossic situations abound across the world; some examples include bidialectal use of Austrian dialects like Styrian or Tyrolean vs. Standard Austrian German, or of Swiss German or Alemannic vs. Standard Swiss German. Thus, the two dialects studied here constitute varieties of the kind that are part of the natural continuum of socio-linguistic variation frequently encountered and flexibly used by monolinguals.

The first dialect we investigate is Öcher Platt, a variety of the West Germanic dialect continuum spoken in and around the German city of Aachen. It has been in continuous decline since WWII and is currently spoken predominantly by the older generation. It has no written standard and no literary tradition, and there is no formal schooling in this dialect. While estimates of lexical overlap with Standard German are not available, this overlap is likely to be substantial as the main differentiating feature of Öcher Platt is its characteristic prosody. Öcher Platt does not carry the prestige of a minority language; its speakers use it only in certain social contexts and situations.

The second dialect, Dundonian is an urban variety spoken in and around the city of Dundee in Scotland. Like most other Scots dialects (not to be confused with Scottish Gaelic, a Celtic minority language), it has the status of the low, informal variety that is spoken alongside (Scottish) Standard English (Johnston Jr., 2007). Dundonian is characterised by a number of regular phonetic changes such as monophthongisation (e.g. Standard English 'mouse' /mars/ vs. Dundonian 'moose' /mu:s/) or vowel changes (e.g. Standard English 'glasses' /głasız/ vs. Dundonian 'glesses' /głesiz/) and a small amount of lexical variation (e.g. Standard English 'children' vs. Dundonian 'bairns'). Although there is a Scots dialect literature, orthography has not been standardised for most varieties of Scots (Costa, 2015). Furthermore, despite the fact that for socio-political and historical reasons Scots dialects are sometimes classified as belonging to a minority language (Stuart-Smith, 2004), many bidialectal speakers do not think of Scots as a language, with $64 \%$ of respondents to a recent Scottish Government (2010) survey considering it as "just a way of speaking".

\section{The present study:}

We tested German and English bidialectal speakers using a dialect-switching task with cognate and non-cognate words to examine the existence of dialect switching 
costs and inter-dialectal cognate facilitation effects. Similarly to highly proficient, balanced bilinguals, we expected to see symmetrical switching costs and cognate facilitation effects, and possibly an interaction between the two effects. As both of these effects have been interpreted as arising from co-activation of language-specific lexical representations, their existence in bidialectals would suggest that routine use of a socio-linguistic variety might require separate lexical entries for each of the different varieties. Such a conclusion, in turn, would invoke the necessity to postulate cognitive control mechanisms that allow speakers to select the appropriate target words based on the social context of a communicative situation, a conclusion that should cast doubt on claims that exercising language control is unique to bilinguals: If monolinguals frequently need to juggle different dialects or registers then their language control mechanisms might not really be different from those in bilinguals.

In addition to testing proficient bidialectal speakers, we also tested a group of monodialectal speakers who were taught the dialect words prior to the experiment, to see whether the sparse lexical representations associated with early stages of dialect proficiency lead to asymmetric switch costs with longer latencies when switching back into the dominant variety. This would provide further evidence that monolinguals who encounter a new socio-linguistic variety have to exercise similar inhibitory language control mechanisms as low-proficiency unbalanced bilinguals.

\section{Experiment 1: Dialect switching in German}

\section{Method}

Participants: We tested thirty-two native speakers of German residing in the city of Aachen (17 women) aged between 47 and 82 years (mean age 64.9 years, s.d. 10.0 years). Participants were asked to rate their ability to comprehend and produce Öcher Platt on a scale from 1 (very bad) to 7 (very good). Their mean self-ratings were very high ranging from 5-7 (comprehension: mean 6.5, s.d. 0.57; production: mean 6.3, s.d. 0.72). However, participants differed considerably with respect to self-reported amount of daily usage of Öcher Platt, which ranged from $10-90 \%$ of the time; mean usage $38.1 \%$ (s.d. 16.5). We also obtained information on participants' education level which was fairly evenly distributed across different levels with eight university graduates, eight participants having obtained British A-level or International Baccalaureate equivalent, ten participants having obtained British GSCE equivalent and six participants having left school before obtaining formal qualifications, which in Germany often entails embarking on vocational training. Furthermore, we obtained background information about participants' knowledge of other languages. Overall, 22 participants $(69 \%)$ of participants had studied one or more foreign languages and rated their proficiency in their most-studied language on average as 4.6 (s.d. 1.4) on a scale ranging from 1 (low proficiency) to 7 (native-like proficiency), qualifying them as medium-proficiency foreign language learners, and not balanced bilinguals.

While no participants reported any neurological or other deficiencies, we conducted the DemTect, prior to the experiment, to test for mild cognitive impairment or dementia at an early stage (Kalbe et al., 2004; Kessler, Calabrese, Kalbe, \& Berger, 2000). The transformed DemTect total score, with a maximum score of 18 , is independent of education and age. Scores ranging from 9 to 12 points indicate mild cognitive impairment, while scores of 8 and below indicate dementia. Participants' scores ranged from 12 to 18 with a mean score of 16.4, s.d. 1.7, indicating that these 
bidialectals did not exhibit signs of age-related cognitive impairment. All participants were reimbursed $5 €$ for their participation.

Materials: We selected 18 black-and-white pictures from Bates et al. (2003). Nine of the associated words were cognates between standard German and Öcher Platt (e.g. 'Eimer - Emmer'); the other 9 were non-cognates (e.g. 'Auto - Wajjel'). The list of words can be found in Appendix 1. Cognates and non-cognates were assembled into separate blocks, with each word repeated 4 times resulting in 72 trials per block.

To ensure that standard and dialect cognates and non-cognates were matched in terms of word length and word frequency, we first compared the word length in phonemes and syllables across the four types of words using a two-way ANOVA with Linguistic Variety (standard vs. dialect) and Cognate Status (cognate vs. non-cognate) as between-item factors. While there were no differences in word length in terms of number of phonemes (all p-values $>.3$ ) there was a tendency for the average syllable length of dialect words of 1.7 to be shorter to the average syllable length of 2.1 for the standard words, although this difference did not reach significance $(F(1,32)=2.7, p=$ .11). Still, the small length difference may make overall faster naming latencies for dialect words somewhat more likely. As word frequency estimates for dialect words are not available, we compared word frequency only between standard German cognates and non-cognates using both the Celex database for German retrieved from http://celex.mpi.nl/ and the Leeds corpus retrieved from http://corpus.leeds.ac.uk/frqc/internet-de-forms.num. None of the estimates yielded a difference in terms of log word frequency per million (all p-values $>.5$ ).

Procedure: Participants first completed a Dialect Usage Questionnaire, inquiring about their place of residence and linguistic background, including percent of spoken usage of all varieties and self-ratings of their ability to understand and produce Öcher Platt. Next, the dialect-switching task was then presented using E-Prime. First, participants received a practice block in which they were asked to name all pictures in Öcher Platt and in Standard German, in randomised order, to familiarise themselves with the materials and the task. After the presentation of each picture, the name in both languages was presented under the picture.

After getting acquainted with the pictures, participants were presented with two pure cognate and two pure non-cognate blocks in alternating order with cognate status of starting block counterbalanced across participants; each block contained 72 trials. Within each block, item sequence was determined using two pseudorandomised lists, which were constructed to ensure a roughly equal number of times an item appeared in switch (50.7\%) and non-switch (49.3\%) trials while maintaining unpredictability of trial type. As a result, $54.1 \%$ of switches occurred after one trial, $17.9 \%$ of switches occurred after two trials of the same variety, $17.2 \%$ of switches occurred after three trials of the same variety, and the remaining $11 \%$ after four to eight trials of the same variety. Participants were instructed to name the pictures as quickly and accurately as possible, omitting extraneous vocalisations and selfcorrections, in either Standard German or Öcher Platt, depending on the colour of the border surrounding the picture. The combination of border colour (blue vs. green) with variety (Standard German vs. Öcher Platt) was counterbalanced across participants.

During each trial, the target picture was presented simultaneously with the language cue (i.e., the coloured border), and remained on the screen until a response was given. The next trial started $1250 \mathrm{~ms}$ after onset of the participants' response. 
Participants' responses were audio-recorded using an AudioTechnica ATR20 low impedance uni-drectional microphone, and naming latencies were measured from the onset of picture presentation until the participants' response triggered the voice key of the PST Systems Serial Response Box.

Design: The independent variables were Linguistic Variety (Standard German vs. Öcher Platt), Cognate Status (cognate vs. non-cognate) and Trial Type (switch vs. non-switch). Linguistic Variety and Trial Type were manipulated within participants and within items (images) while Cognate Status was manipulated within participants and between items. The dependent variables were error rates and naming latencies.

\section{Results}

Error rates: Trials in which participants produced an extraneous vocalisation, the wrong word or the correct word in the wrong variety were coded as errors. The mean percentages of errors per condition are listed in the top part of Table 1. The overall error rate was $5.1 \%$. Prior to conducting statistical analyses all first trials of a block, which are undefined as to Trial Type (1.4\%), were excluded. Error rates were analysed using a mixed-effect logit model with crossed random effects of participants and pictures, and centering of all fixed effects. As a model with maximal random effect structure including intercepts and slopes for all main effects and interactions (Barr, Levy, Scheepers \& Tily, 2013) using the model structure Errors $~$ LingVariety $*$ CognateStatus * TrialType + $(1+$ LingVariety * CognateStatus * TrialType | Subject $)+(1+$ LingVariety * TrialType $\mid$ Item) failed to converge, we systematically tested models with different random effect structures in the following way: We started with an intercept-only model, which revealed significant effects of Linguistic Variety, $\beta=0.12, \mathrm{t}=2.44, \mathrm{p}<.05$, Trial Type, $\beta=0.14, \mathrm{t}=2.88, \mathrm{p}<.01$, and their interaction, $\beta=0.11, t=2.17, p<.05$. We then included random slopes corresponding to the fixed effects that had reached significance in the model, to guard against anticonservative inferences about these effects (Barr, Kliegl, Vasishth \& Baayen, 2015). This resulted in inclusion of random slopes for Linguistic Variety, Trial Type and their interaction by participants and by items. This model $($ AIC $=3470)$, albeit not significantly different from the random-intercept-only model (AIC $=3446$ ) as determined using a likelihood-ratio test, $\chi^{2}=11.78, \mathrm{df}=18, \mathrm{p}=.86$, only yielded a main effect of Trial Type, $\beta=0.26, \mathrm{t}=2.93, \mathrm{p}<.01$. This analysis leads us to conclude that the most conservative interpretation of the error data is one that only acknowledges an effect of Trial Type indicating that participants overall made more errors in switch $(5.8 \%)$ than in non-switch trials $(4.5 \%)$.

Naming latencies: For the analyses of naming latencies, recovery trials following an error $(2.9 \%)$ as well as items with latencies below $150 \mathrm{~ms}$, above 3000 $\mathrm{ms}$ or greater than 3 standard deviations above the participant mean $(8.9 \%)$ were excluded from the correct trials. Together with the excluded error and first trials this resulted in the exclusion of $15.7 \%$ of data points. The data were fitted to a mixedeffect model with fixed effects of Linguistic Variety, Cognate Status and Trial Type and the maximal random effect structure, which failed to converge. Model selection was then carried out as for the error analyses: An intercept-only model yielded effects of Linguistic Variety, $\beta=8.40, t=2.34, p<.05$, Cognate Status, $\beta=54.17, t=3.10$, $p$ $<.01$, and Trial Type, $\beta=53.25, \mathrm{t}=14.65, \mathrm{p}<.001$, as well as of the interaction between Cognate Status and Trial Type, $\beta=9.06, \mathrm{t}=2.49, \mathrm{p}<.05$. We then fitted a model containing all slopes associated with the significant effects of the structure 
Latencies $\sim$ LingVariety $*$ CognateStatus $*$ TrialType $+(1+$ LingVariety + CognateStatus * TrialType $\mid$ Subject $)+(1+$ LingVariety + TrialType $\mid$ Item $)$, which yielded effects of Cognate Status, $\beta=53.57, \mathrm{t}=2.91, \mathrm{p}<.01$, and Trial Type, $\beta=$ $53.90, \mathrm{t}=7.50, \mathrm{p}<.001$. Model comparison using a likelihood-ratio test between the intercept-only model $(\mathrm{AIC}=111677)$ and the model containing associated random slopes $(\mathrm{AIC}=111575)$ indicated superior fit of the latter, $\chi^{2}=140.3$, df $=19, p<$ .001 , suggesting that the most conservative interpretation of the data confirms overall faster latencies by $104 \mathrm{~ms}$ for non-switch compared to switch trials, and overall faster latencies by $108 \mathrm{~ms}$ for cognate compared to non-cognate items, as illustrated in the left panels of Figure 1. Note that the upper left panel depicts latencies for the two linguistic varieties to indicate that the overall latencies as well as the switch costs were of very similar magnitude when participants named pictures in Standard German and in Öcher Platt.

Table 1: Mean naming latencies in ms (top row) and percent of errors (bottom row) as a function of linguistic variety, cognate status and trial type for German-Öcher Platt bidialectals (Experiment 1), English-Dundonian bidialectals and English monodialectals (Experiment 2). Standard deviations, computed with participant as random effect, are given in parentheses.

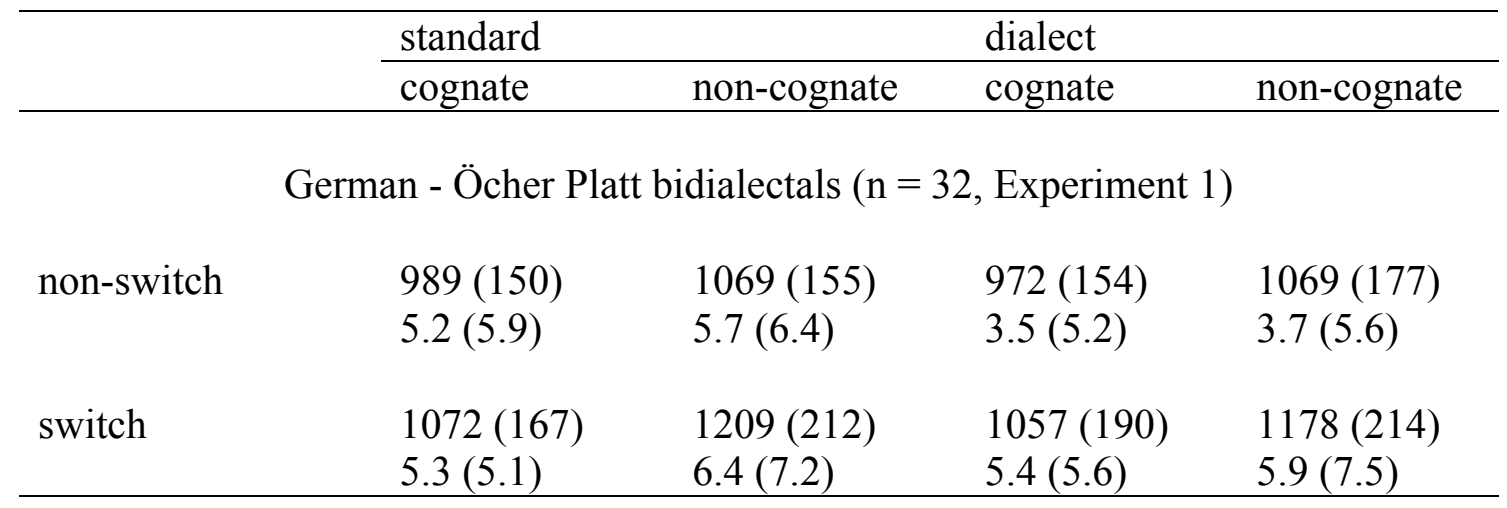

English-Dundonian bidialectals $(\mathrm{n}=32$, Experiment 2$)$

\begin{tabular}{lllll} 
non-switch & $817(165)$ & $1015(192)$ & $839(192)$ & $956(186)$ \\
& $1.4(2.3)$ & $3.7(5.1)$ & $3.4(4.4)$ & $3.0(3.9)$ \\
\multirow{2}{*}{ switch } & & & & \\
& $871(179)$ & $1094(234)$ & $877(191)$ & $1060(231)$ \\
& $1.9(3.8)$ & $4.1(4.7)$ & $2.6(3.4)$ & $4.3(5.1)$ \\
\hline
\end{tabular}

English monodialectals $(\mathrm{n}=16$, Experiment 2$)$

\begin{tabular}{lllll} 
non-switch & $858(118)$ & $1026(156)$ & $927(137)$ & $1026(179)$ \\
& $3.1(3.3)$ & $5.1(6.4)$ & $3.1(5.5)$ & $3.7(3.3)$ \\
\multirow{2}{*}{ switch } & & & & \\
& $994(178)$ & $1174(203)$ & $989(185)$ & $1123(257)$ \\
& $3.5(5.1)$ & $9.1(6.5)$ & $6.7(3.3)$ & $5.5(6.2)$ \\
\hline
\end{tabular}



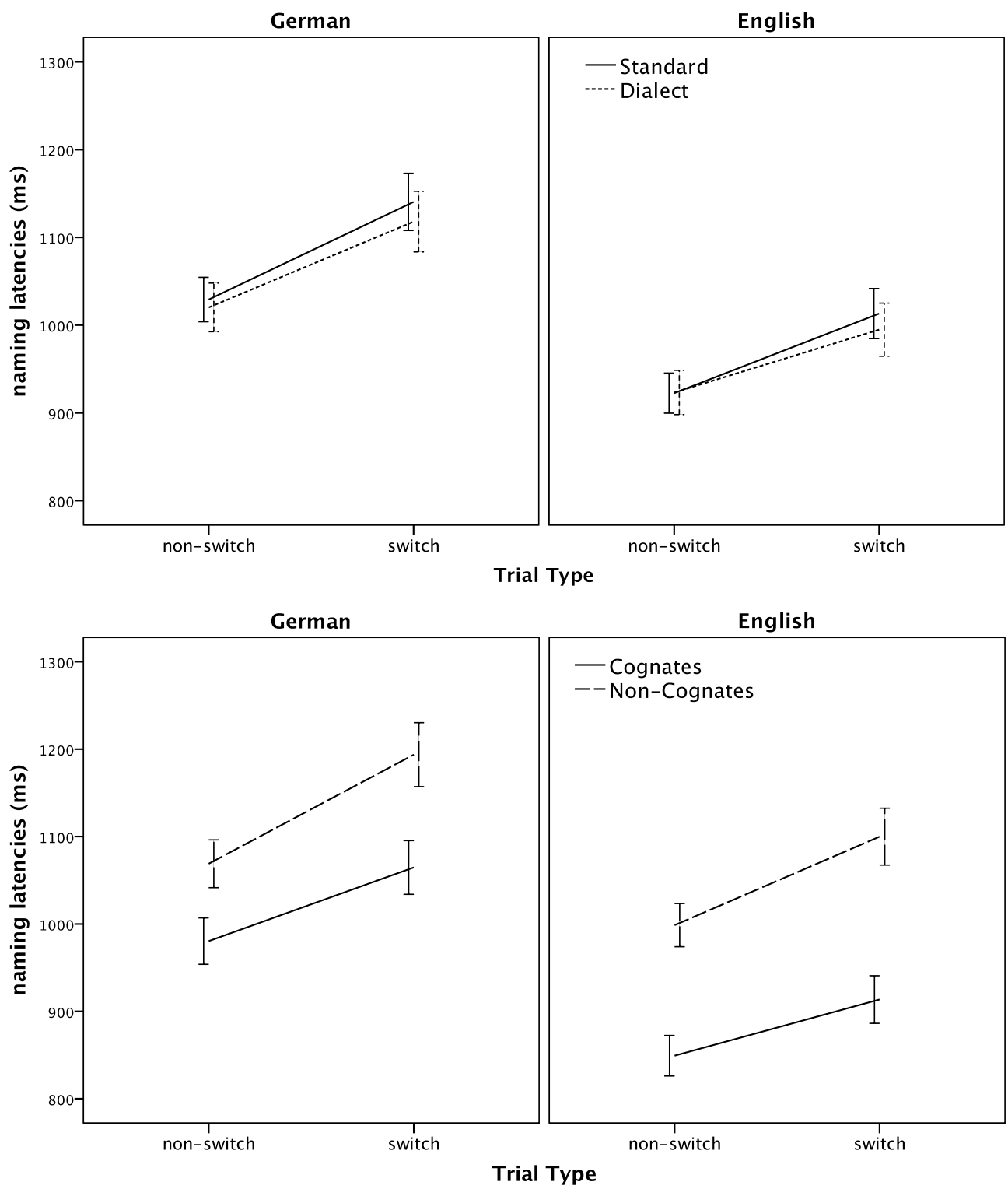

Figure 1: Naming latencies for non-switch and switch trials as a function of linguistic variety (upper panels) and cognate status (lower panels) for bidialectal native speakers of German examined in Experiment 1 (left panels) and bidialectal native speakers of English examined in Experiment 2 (right panels). Error bars display +/- 1 S.E.M. computed with participants as random effect.

As previous findings from highly proficient, balanced bilinguals demonstrated symmetrical switch costs in an L3 (Costa \& Santesteban, 2004; Costa et al., 2006), a potential concern is that the symmetrical switch costs in bidialectals could be related to their L2 proficiency: If proficiency in other languages attenuates the potential switch cost asymmetry for dialect words, then the observed symmetrical switch cost may have been due to participants' knowledge of other languages. Although our participants did not fall into the category of balanced bilinguals, and reported higher proficiency in the use of the dialect than the L2, it still seemed prudent to check whether knowledge of L2 may have influenced our results. Because 22 out of the 32 participants had studied one or more foreign languages (predominantly English, 
followed by Dutch or French), and 16 of them had attained a self-reported proficiency higher than 3.5 on a scale from 1 to 7 , we checked whether the effects of Cognate Status and Trial Type differed as a function of self-reported proficiency in foreign languages and percent of dialect use. To this end, we included the proficiency rating for the highest-rated foreign language as well as the percentage of daily dialect use as fixed effects into a mixed-effect model which included all 2-way interactions as well as the 3-way interactions between Dialect Use, Variety and Trial Type and between L2 proficiency, Variety and Trial Type, using the same model-fitting strategy as described above where random slopes of the significant effects obtained with an intercept-only model were included in the final version. This model confirmed the effects of Trial Type, $\beta=53.8, \mathrm{t}=7.2, \mathrm{p}<.001$, and of Cognate Status, $\beta=52.5, \mathrm{t}=$ $2.9, \mathrm{p}<.05$. Crucially, none of the 2 -way or 3 -way interactions reached significance (all p's $>$.19) suggesting that the magnitude of the participants' switch costs and cognate facilitation effects when naming standard vs. dialect words was not related to their knowledge of other languages or their daily dialect use.

\section{Discussion}

The results of Experiment 1 revealed that bidialectal speakers of Standard German and Öcher Platt exhibited costs when switching between the two varieties in a picture-naming task. Switch costs manifested themselves both in error rates as well as in naming latencies. This finding indicates that monolinguals who routinely use a dialect variety of their native language show evidence for language control processes that are compatible with an architecture of the lexicon in which competing lexical representations are tagged for variety (e.g. dialect) membership, and successful language use requires selective activation of schemas corresponding to the different varieties. Thus, cued switching between closely related linguistic varieties in monolinguals incurs similar costs as switching between different languages does in balanced bilinguals (Bobb \& Wodniecka, 2013) suggesting that similar mechanisms of language control operate during lexical activation in two very closely related varieties of a language. However, before considering the theoretical implications of this finding Experiment 2 sought to obtain further cross-linguistic evidence for costs of bidialectal switching, particularly in light of the considerable variability in age and in self-reported frequency of dialect use amongst participants. Indeed, the correlation between age and switch cost was significant ${ }^{1}, \mathrm{r}=.38, \mathrm{n}=21, \mathrm{p}<.05$, in line with findings that older participants can demonstrate larger switch costs (Gollan \& Ferreira, 2009; Weissberger, Wierenga, Bondi, \& Gollan, 2012), suggesting that it is possible that the observed switch costs may have been exaggerated. Experiment 2 will therefore attempt to replicate this effect with younger participants. It will also explore the role of dialect proficiency in dialect switching more directly.

Our results also revealed a cognate facilitation effect similar to the one reported in the bilingual picture naming literature (Costa et al., 2000; Christoffels et al., 2007; Declerck, et al., 2012): Bidialectal cognates were generally named faster and more accurately. Cognate facilitation is indicative of dual language activation, either due to shared phonological representations, which are being activated in a cascading fashion (Costa, et al. 2000), or due to feedback from the phonological level to the lemma level (Bernolet, Hartsuiker, \& Pickering, 2012). In the context of bidialectism, the amount of cognate facilitation can be interpreted as an indicator for degree of concurrent activation of both varieties. However, unlike Declerck et al. (2012), we did not find statistically significant effects of reduced switching costs in 
cognates, although the data showed a trend in this direction. Still, the lack of a significant effect casts some doubt on the idea that facilitation arising through phonological co-activation of the non-target dialect cognates can alleviate switch costs.

\section{Experiment 2}

To obtain corroborating cross-linguistic evidence for the existence of switch costs associated with dialect use, Experiment 2 tested younger adult Scottish bidialectal speakers of Standard English and Dundonian Scots. Given the considerable overlap between (Scottish) Standard English and Dundonian in terms of phonology, syntax and lexicon, use of both varieties is similar to use of Standard German and Öcher Platt in the bidialectals examined in Experiment 1. We therefore expect a similar switch cost pattern to arise in this bidialectal population.

In addition to providing cross-linguistic support for the mere existence of costs associated with dialect switching, we also sought to examine whether unbalanced bidialectals with demonstrably lower proficiency in the dialect compared to the standard variety of their native language would exhibit asymmetric switch costs as observed in unbalanced bilinguals. It is unclear from previous research as to what constitutes balanced proficiency in two languages or linguistic varieties: is it similarity in the frequency of passive encounter, or similarity in the frequency of active use of a variety that determines the degree of proficiency that results in balanced switch costs? If limited active dialect use results in proficiency differences similar to those found in unbalanced bilinguals, then passive, but not active, bidialectals should exhibit asymmetric switch costs: just like unbalanced bilinguals it should take them longer to switch back into the more familiar, dominant variety because greater inhibition of this variety needs to be overcome (Filippi, Karamini \& Thomas, 2014; Meuter \& Allport, 1999; Schwieter \& Sunderman, 2008). However, in digossic regions long-term passive exposure to the local dialect may strengthen lexical representations of the dialect sufficiently so as not to lead to proficiency differences and associated switch cost asymmetries. Experiment 2 tackles this question by analysing bidialectals in terms of active vs. passive dialect use and compares switch costs in these two groups to a group of monodialectal speakers who had limited dialect exposure and were trained on dialect words prior to the experiment. The monodialectals were speakers of Standard Anglo-English who had recently moved to the Dundee area from England and had only had limited exposure to Dundonian. The choice of an Anglo-English monodialectal control group was necessary due to the fact that widespread distribution of various Scots dialects makes it very difficult to find true monodialectals in Scotland. For these monodialectal speakers we expect a clear proficiency difference between Dundonian and Standard English, which should result in a switch cost asymmetry.

\section{Method}

Participants: Forty-eight adult native English speakers (mean age $=30.15$ years, s.d. $=10.98$ years, range $=18-54$ years) participated in the dialect-switching experiment. Thirty-two participants were English-Dundonian bidialectals; another sixteen were monodialectal speakers of Standard (Anglo) English who had moved from England to the area of Dundee very recently. Five additional participants (three bidialectals, two monodialectals) were excluded for the following reasons: Two participants were over 
the age of 60 and were excluded as Experiment 1 had identified that 60 marks the age at which switch costs start to increase; one bidialectal participant was from an area of Scotland outside of the dialect region from which the stimuli were selected; one Anglo-English participant reported using another regional English dialect over 30\% of the time which differentiated this participant from the other monodialectals who did not report using any other regional dialect, and one participant had latencies more than 3 standard deviations above the mean for all participants. We also recruited eight participants as dialect pronunciation raters. Participants were reimbursed for experiment participation as follows: bidialectal participants - $£ 5$, monodialectal participants - $£ 10$ (to compensate for the greater time commitment associated with dialect training; see Procedure), and dialect pronunciation raters - $£ 10$.

Participants completed a Background Questionnaire, which included a Dialect Usage part (see Appendix 2). All background variables are presented in Table 2. As in Experiment 1, participants were asked to rate their ability to comprehend dialect on a scale from 1 ('can't understand') to 7 ('completely understand'). To further assess familiarity with Dundonian, participants were shown the eighteen experimental stimuli with their Standard English labels and asked to name them in Dundonian.

To confirm whether the group differences in lexical knowledge of the dialect were in line with participants' ability to pronounce Dundonian, a selection of three audio-taped naming responses per participant obtained in the dialect-switching experiment (135 responses in total; audio files for two bidialectals and one monodialectal were unusable due to software problems that occurred after error coding had been completed) was rated by eight participants ( 3 males, 23 - 59 years) who were proficient speakers and users of both Standard (Scottish) English and Dundonian. These responses were rated with respect to authenticity of native Dundonian pronunciation using a visual analogue rating scale on the screen with "not good" marked on the left hand side at the 450 pixel position, and "very good" marked on the right-hand side at the 1250 pixel position. The intra-class correlation between the averaged ratings per participant for the eight raters was .73 which indicates good to excellent agreement.

Participants were also compared with respect to their socio-economic status and knowledge of foreign languages. Socio-economic status was assessed based on level of education, to maintain comparability with the German data. Participants differed from the German-Öcher Platt bidialectals tested in Experiment 1 in these two variables: $84 \%$ of the English-Dundonian bidialectals were college and university graduates (see Table 2), which was a significantly higher percentage compared to the German-Öcher Platt bidialectals, $\chi^{2}=8.6, \mathrm{df}=1, \mathrm{p}<.01$. Knowledge of foreign languages was significantly lower compared to the German-Öcher Platt bidialectals, as only 10 participants reported having studied one or more foreign languages, compared to 22 in Experiment $1, \chi^{2}=9.0, \mathrm{df}=1, \mathrm{p}<.01$. Using the same scale as in Experiment 1, participants rated their L2-proficiency on average as 2.9 (s.d. 0.9), which was significantly lower than in the German-Öcher Platt bidialectals, $t(31)=$ $3.70, \mathrm{p}<.001$. Crucially, however, although the English-Dundonian bidialectals were significantly younger, $\mathrm{t}(62)=11.4, \mathrm{p}<.001$, better educated and less familiar with other languages than the German-Öcher Platt bidialectals, they were not different with respect to self-reported dialect comprehension ability $(\mathrm{p}=1.0)$ and percent of selfreported dialect use $(\mathrm{p}=.30)$.

As the second aim of this experiment was to investigate the effect of dialect proficiency on switch costs, we divided bidialectal participants into two groups based on a median-split of percentage of daily dialect use reported in the Dialect Usage 
Questionnaire. Bidialectals who reported using the dialect more than $28 \%$ of time ( $\mathrm{n}=$ 16) were categorised as active bidialectals; those who used the dialect less as passive bidialectals $(\mathrm{n}=16)$. These labels take account of the fact that only dialect usage but not dialect comprehension, translation accuracy and pronunciation differed between these two subgroups (see Table 2). We also asked participants about their attitudes towards dialect usage, and found no difference between active and passive dialect users on a composite attitude score consisting of the average for eight attitude-related questions (see Appendix 2), four of which were reverse-coded. Monodialectal speakers, on the other hand, scored lower in age, years they had resided in Dundee, comprehension of Dundonian, correctly translated words and authenticity of Dundonian pronunciation due to their Anglo-English accent despite the fact that they were able to correctly produce the words (see Table 2). We also found that while education levels were evenly distributed among monodialectals, they had not yet reached the same education level as the bidialectals, $\chi^{2}=7.7$, df $=2, p<.05$, presumably on account of their younger age and therefore not yet having completed their degree. 
Table 2: Means and standard deviations (in parentheses) of background variables as well as results of a univariate ANOVA comparing the three groups as well as number of participants having attained different levels of education. Asterisks indicate the $\mathrm{p}$ value $(* * * \mathrm{p}<.001, * * \mathrm{p}<.01, * \mathrm{p}<.05)$ and are placed next to the mean that was significantly different from the other two means based on Bonferroni-corrected posthoc tests.

\begin{tabular}{|c|c|c|c|c|}
\hline & \multicolumn{2}{|c|}{ bidialectals } & \multirow{2}{*}{$\begin{array}{l}\text { monodialectals } \\
(\mathrm{n}=16)\end{array}$} & \multirow[t]{2}{*}{$\mathrm{F}(2,45)$} \\
\hline & $\begin{array}{l}\text { active } \\
(\mathrm{n}=16)\end{array}$ & $\begin{array}{l}\text { passive } \\
(\mathrm{n}=16)\end{array}$ & & \\
\hline Age & $\begin{array}{l}34.75 \\
(10.44)\end{array}$ & $\begin{array}{l}33.68 \\
(12.68)\end{array}$ & $\begin{array}{l}22.50^{* *} \\
(3.03)\end{array}$ & 7.92 \\
\hline Years residing in Dundee & $\begin{array}{l}32.69 \\
(9.55)\end{array}$ & $\begin{array}{l}28.69 \\
(11.82)\end{array}$ & $\begin{array}{l}2.53 * * * \\
(3.626)\end{array}$ & 52.76 \\
\hline $\begin{array}{l}\text { Percent use of Standard } \\
\text { English }\end{array}$ & $\begin{array}{l}46.88 * * * \\
(17.97)\end{array}$ & $\begin{array}{l}87.13 \\
(9.22)\end{array}$ & $\begin{array}{l}96.87 \\
(7.04)\end{array}$ & 73.72 \\
\hline $\begin{array}{l}\text { Self-rated Dundonian } \\
\text { comprehension }\end{array}$ & $\begin{array}{l}6.69 \\
(.48)\end{array}$ & $\begin{array}{l}6.31 \\
(.87)\end{array}$ & $\begin{array}{l}4.63 * * * \\
(1.63)\end{array}$ & 15.91 \\
\hline $\begin{array}{l}\text { Attitudes towards } \\
\text { Dundonian }(1-7)\end{array}$ & $\begin{array}{l}4.50 \\
(1.38)\end{array}$ & $\begin{array}{l}3.89 \\
(1.19)\end{array}$ & $\begin{array}{l}4.30 \\
(1.00)\end{array}$ & 1.09 \\
\hline $\begin{array}{l}\text { Correctly translated } \\
\text { Dundonian words (out of 18) }\end{array}$ & $\begin{array}{l}18.00 \\
(0)\end{array}$ & $\begin{array}{l}17.88 \\
(0.34)\end{array}$ & $\begin{array}{l}5.19 * * * \\
(2.81)\end{array}$ & 324.64 \\
\hline $\begin{array}{l}\text { Authenticity rating of native } \\
\text { Dundonian pronunciation }\end{array}$ & $\begin{array}{l}1048.16 \\
(109.75)\end{array}$ & $\begin{array}{l}1050.62 \\
(92.01)\end{array}$ & $\begin{array}{l}646.31 * * * \\
(114.39)\end{array}$ & 64.01 \\
\hline \multicolumn{5}{|l|}{ Number of participants } \\
\hline A-level/Higher school exams & 1 & 4 & 8 & \\
\hline College degree & 4 & 6 & 5 & \\
\hline $\begin{array}{r}\text { University degree/ } \\
\text { postgraduate }\end{array}$ & 11 & 6 & 3 & \\
\hline
\end{tabular}

Materials: Eighteen words and their corresponding pictures were selected (see Appendix 1). Nine of the words were cognates between Standard English and Dundonian (e.g. 'mouse - moose'); the other 9 were non-cognates (e.g. 'children bairns') and were assembled into separate blocks, with each word repeated 4 times resulting in 72 trials per block. The corresponding pictures were black-and-white line drawings downloaded from various internet sources as corresponding pictures were not available in the Snodgrass and Vanderwart (1980) set.

As with the materials for Experiment 1, we compared the four types of words in terms of length in phonemes and syllables using a two-way ANOVA with 
Linguistic Variety (standard vs. dialect) and Cognate Status (cognate vs. non-cognate) as between-item factors to check whether standard and dialect cognates and noncognate words were matched. There were no differences in word length in terms of number of phonemes (all p-values > .3). As for German, word frequency estimates for dialect words are not available; we therefore compared log word frequency only for Standard English cognates and non-cognates using the CELEX-database retrieved from http://celex.mpi.nl/. This comparison revealed no significant difference, $\mathrm{p}=.8$.

Procedure: Participants were first provided with a brief outline of the differences between Standard English and Dundonian Scots, and examples of each variety not used in the experiment (e.g. 'old vs. auld', 'know vs. ken'), to clarify which linguistic varieties were targeted in this experiment. They then completed the Dialect Usage Questionnaire, inquiring about their place of residence and linguistic background, including percent of usage of all varieties spoken and self-ratings of their ability to understand Dundonian. Participants were shown the stimuli and asked whether they were familiar with any of the Dundonian names for the pictures. The monodialectal participants were trained by listening to a native Dundonian producing the dialect words. Each item was presented four times and the participant had the option to repeat this block as many times as they wished. Once the monodialectals felt fully familiar with all the Dundonian items, they were asked to produce each item twice to ensure they had learned the Dundonian words. Bidialectals were also asked to produce each item to ensure they were familiar with the dialect and standard version. The dialectswitching task was then presented in exactly the same way as in German using the same E-Prime script with an AudioTechnica ATR20 low impedance uni-drectional microphone, and the voice key of the PST Systems Serial Response Box for measurement of naming latencies. As in Experiment 1, randomisation ensured a roughly equal number of times that an item appeared in switch $(50.7 \%)$ and nonswitch $(49.3 \%)$ trials while maintaining unpredictability of trial type. The distribution of switch trials was similar to Experiment 1 such that $45.6 \%$ of switches occurred after one trial, $26.5 \%$ of switches occurred after two trials of the same variety, $22.1 \%$ of switches occurred after three trials of the same variety, and the remaining $6 \%$ after four to seven trials of the same variety.

Design: To check whether the findings from German-speaking bidialectals reported in Experiment 1 can in general be replicated cross-linguistically, data for active and passive English-speaking bidialectals were analysed jointly using the same design as in Experiment 1 where the independent variables were Linguistic Variety (Standard English vs. Dundonian), Cognate Status (cognate vs. non-cognate) and Trial Type (switch vs. non-switch). Linguistic Variety and Trial Type were manipulated within participants and within items (images) while Cognate Status was manipulated within participants and between items.

To further examine switch costs as a function of dialect proficiency, active and passive bidialectals were compared to the group of monodialectals. For this analysis, the independent variables were Dialect Group (active bidialectals, passive bidialectals, monodialectals), Linguistic Variety (Standard English vs. Dundonian), Cognate Status (cognate vs. non-cognate), and Trial Type (switch vs. non-switch). Dialect Group was manipulated between participants only. Linguistic Variety and Trial Type were manipulated within participants and within items (images). Cognate Status was manipulated within participants and between items. The dependent variables for both analyses were error rates and naming latencies. 


\section{Results}

Analysis of bidialectals: To compare the pattern of switch costs to Experiment 1 we first analysed the results from the bidialectal participants only.

Error rates: Trials in which participants produced an extraneous vocalisation, the wrong word or the correct word in the wrong variety were coded as errors. The mean percentages of errors per condition are listed in the bottom part of Table 1. The overall error rate was $3.0 \%$. First trials of a block, which are undefined as to Trial Type (1.4\%), were excluded prior to any further analyses. The error data were submitted to a mixed-effect model with crossed random effects of participants and items with centered fixed effects of Linguistic Variety, Cognate Status and Trial Type. As the model with random effect structure did not converge, we used the same model-fitting strategy as in Experiment 1. The resulting model of the structure Error $\sim$ LingVariety * CognateStatus * SwitchType $+(1+$ LingVariety $*$ CognateStatus Subject $)+(1+$ LingVariety $\mid$ Item $)$ yielded no significant effects which is not surprising given the overall very low error rate.

Naming latencies: For the analyses of naming latencies, trials that were invalidated due to voice key problems $(0.5 \%)$, errors $(3.0 \%)$, recovery trials following an error $(3.9 \%)$ as well as items with latencies below $150 \mathrm{~ms}$, above $3000 \mathrm{~ms}$ or greater than 3 standard deviations above the participant mean $(2.1 \%)$ were excluded. The remaining $91 \%$ of trials were submitted to a mixed-effect model of similar effect structure as the logit model used for the error analyses. The means and standard deviations for each condition can be found in the bottom part of table 1. As a model with maximal random effect structure did not converge, the same model-fitting strategy as in Experiment 1 was applied resulting in a model of the structure ReactionTime $\sim$ LingVariety $*$ CognateStatus $*$ TrialType $+(1+$ LingVariety + CognateStatus + TrialType + LingVariety : CognateStatus + CognateStatus : TrialTypec $\mid$ Subject $)+(1+$ TrialType $*$ LingVariety $\mid$ Item $)$. This model yielded effects of Trial Type, $\beta=34.0, t=6.09, p<.001$, Cognate Status, $\beta=88.16, t=7.17$, $\mathrm{p}<.001$, and of the interaction between Linguistic Variety and Cognate Status, $\beta=$ $15.79, \mathrm{t}=3.61, \mathrm{p}<.01^{2}$. These results demonstrate that naming latencies were faster overall by $68 \mathrm{~ms}$ for non-switch compared to switch trials, and by $180 \mathrm{~ms}$ for cognates compared to non-cognates. The interaction revealed that the cognate facilitation effect was more pronounced in Standard English $(211 \mathrm{~ms})$ than in Dundonian $(150 \mathrm{~ms})$. Because self-reported knowledge of other languages in the eleven participants who had learned an L2 was rather minimal in this sample (mean rating: 2.9) compared to the 22 L2-learners in Experiment 1 (mean rating: 4.6), we did not see reason to include the factor L2 Status into the analyses.

Analysis of sub-groups differing in dialect use: To examine switch costs as a function of proficiency in the dialect variety, we grouped the bidialectals into active and passive dialect users using the median-split of self-reported usage as detailed above, and added the group of monodialectal speakers who were trained on the Dundonian words prior to completing the switching task. Mean error rates and naming latencies for active and passive bilinguals in comparison to monolinguals are given in Appendix 3.

Error analyses: While active and passive bidialectals committed 3.4\% and $2.7 \%$ of errors, respectively, monodialectals committed $4.9 \%$ of errors. First trials of a block were excluded prior to any further analyses. Error rates were analysed using a 
mixed-effect logit model with fixed effects of Dialect Group, Linguistic Variety, Cognate Status and Trial Type, and crossed random effects of participants and items, the latter being defined by the presented images. All fixed effects were centered and the variable Dialect Group was effect-coded with active bidialectals as the reference category. Due to convergence problems with the maximal random effect structure that incorporates intercepts and slopes for all the main effects and interaction we pursued the same model selection strategy as described for Experiment 1. The resulting model expressed by the R-command structure Errors $\sim$ LingVariety * CognateStatus * TrialType * (PassiveBidialectals + Monodialectals $)+(1+$ LingVariety + CognateStatus + LingVariety : CognateStatus + CognateStatus : PassiveBidialectals $\mid$ Subject $)+(1+$ LingVariety $\mid$ Item $)$ yielded an effect of Cognate Status, $\beta=-0.27, \mathrm{t}$ $=-245, p<.05$ indicating fewer errors for cognates compared to non-cognates, as well as an interaction between Trial Type and membership in the monodialectal group, $\beta=-0.21, \mathrm{t}=-1.98, \mathrm{p}<.05$. This model (AIC: 4452 ) provided a significantly better fit to the data than the intercept-only model (AIC: 4467), $\chi^{2}=47.65$, df $=16, p$ $<.001$.

To explore the interaction, we conducted separate analyses using mixed-effect models for each dialect group separately. For active bidialectals, there were no significant effects. For passive bidialectals, we found a main effect of Cognate Status, $\beta=-0.53, \mathrm{t}=-2.19, \mathrm{p}<.05$, indicating fewer errors for cognates than for noncognates. Finally, for monodialectals, the separate analysis confirmed the main effect of Trial Type, $\beta=-0.31, t=-3.31, p<.001$, which showed that the difference between the percentage of errors in switch trials $(6 \%)$ was significantly larger than that in the non-switch trials $(3.7 \%)$.

Naming latencies: For the analyses of naming latencies, trials that were invalidated due to voice key problems $(0.7 \%)$, errors $(4.4 \%)$, recovery trials following an error $(3.9 \%)$ as well as items with latencies below $150 \mathrm{~ms}$, above $3000 \mathrm{~ms}$ or greater than 3 standard deviations above the participant mean were excluded $(2.1 \%)$ from the correct trials. The remaining $88.9 \%$ of trials were analysed using the same model-building strategy as for the errors. The resulting model structure as well as non-standardised coefficients and associated $t$ and $p$-values are provided in Appendix 4.

The results showed a main effect of Trial Type with longer overall latencies for switch trials (1007 ms) than for non-switch trials $(924 \mathrm{~ms})$, which was qualified by a 2-way interaction with Linguistic Variety, indicating that the switch cost of $91 \mathrm{~ms}$ in Standard English was larger than the switch cost of $74 \mathrm{~ms}$ in Dundonian. Trial Type also interacted with membership in the monodialectal group, indicating that the switch costs were larger for monodialectals $(111 \mathrm{~ms})$ than for active $(61 \mathrm{~ms})$ and passive $(76 \mathrm{~ms})$ bidialectals. Crucially, these two interactions were further qualified by a 3-way interaction between Trial Type, Linguistic Variety and membership in the monodialectal group, suggesting that the switch cost asymmetry was due to larger costs switching to Standard English in the monodialectals (see Figure 2).

We also found a main effect of Cognate Status confirming a general cognate facilitation effect of $169 \mathrm{~ms}$, which was qualified by an interaction with Linguistic Variety corroborating for the entire group of participants that had already been found for just the bidialectals in the first analysis, namely that cognate facilitation was larger for Standard English (199 ms) than for Dundonian (139 ms).

To further examine the 3-way interactions between Dialect Group, Trial Type, and Linguistic Variety, we fitted mixed-effect models with maximal random effect structure to naming latencies for each group separately (see Appendix 3). For all three 
groups, this analysis confirmed the effects of Trial Type and Cognate Status as well as the interaction between Linguistic Variety and Cognate Status, which indicated larger cognate facilitation in Standard English. Crucially, only in monodialectals was there a significant interaction between Trial Type and Linguistic Variety (see Figure 2) with larger switch costs in Standard English (139 ms) compared to Dundonian (77 ms) confirming that the 3-way interaction found in the entire sample was carried by the larger switch cost asymmetry in this group.

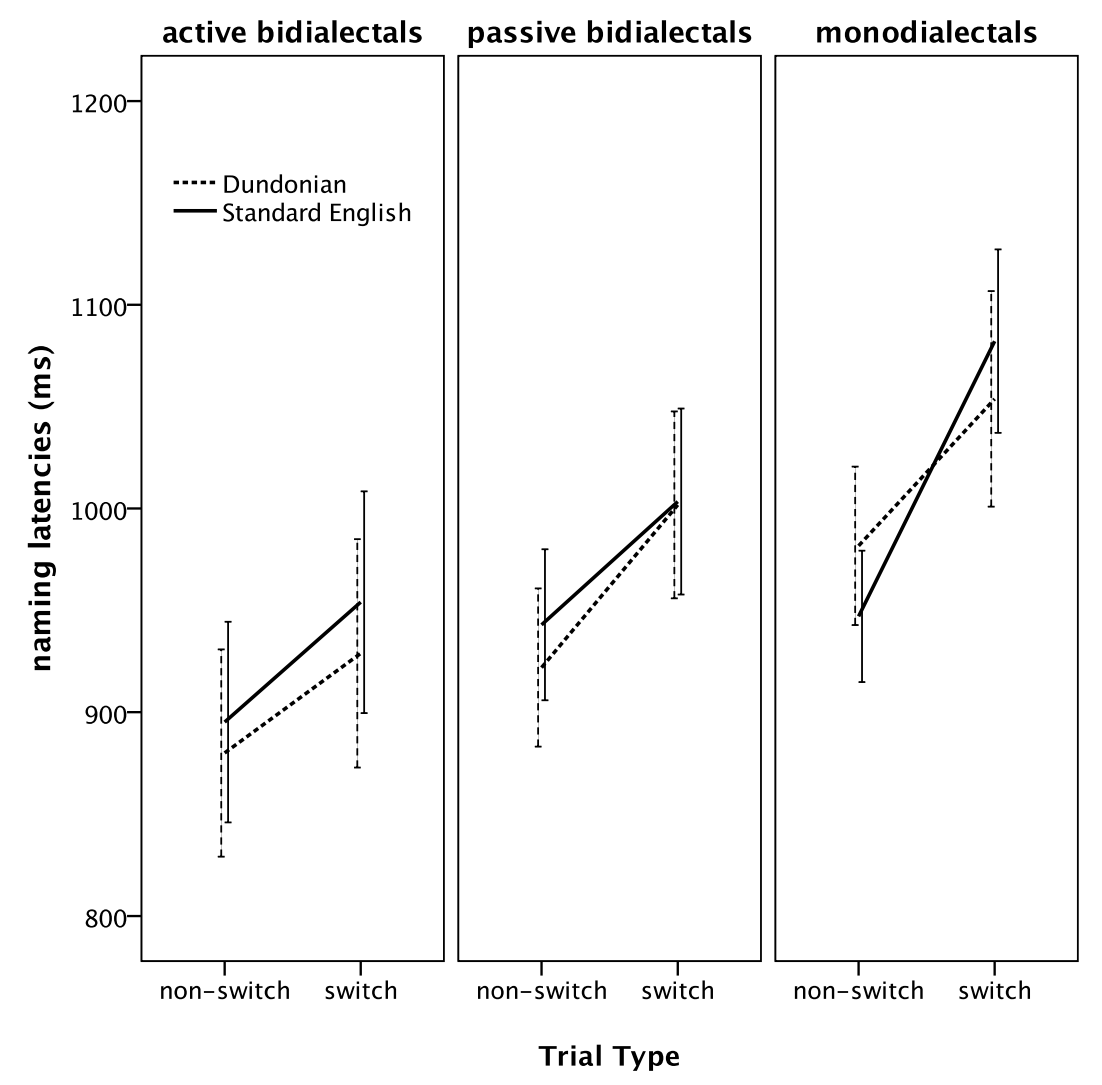

Figure 2: Naming latencies for non-switch and switch trials as a function of linguistic variety (Standard English vs. Dundonian) and dialect group (active bidialectals, passive bidialectals, monodialectals). Error bars display +/- 1 S.E.M. computed with participants as random effect.

\section{Discussion}

Similar to the findings for German bidialectals in Experiment 1, Experiment 2 also revealed a cost associated with switching between dialect varieties, as well as a cognate facilitation effect. The fact that these effects were only observed in the naming latencies is due to the overall lower error rates committed by the considerably younger participants in Experiment 2. Still, despite differences in age and L2 proficiency between participants in Experiment 1 and Experiment 2, and the associated difference in overall naming latency, the main finding of a dialect-related switching cost holds across both experiments. However, cognate facilitation was more pronounced for Standard English indicating that, unlike in Experiment 1, lexical access in the standard variety may have been somewhat more susceptible to influences from phonological representations of the inter-dialectal cognates. A similar 
interaction between language and cognate status has been found in the bilingual picture naming literature, where cognate facilitation effects sometimes are larger in the L1 (Christoffels et al., 2007; Verhoef, Roelofs, \& Chwilla, 2009). It has been suggested that in situations in which both languages are part of the response set, this interaction can arise if L1 is more susceptible to influences from the L2. It is not clear at this point what accounts for the somewhat greater susceptibility of the standard variety to influences from the dialect variety in English, but this subtle cross-linguistic difference does not invalidate the fact that the observed main effects constitute a strong cross-linguistic confirmation for the existence of switch costs and cognate facilitation effects in bidialectals.

When further exploring the effect of dialect proficiency and frequency of dialect usage on switch costs we found that these costs were symmetrical for active and passive bidialectals and asymmetrical for monodialectals with limited familiarity with the dialect. This pattern of results is reminiscent of what is typically found in the bilingual switching literature: balanced bilinguals display switch cost symmetry (Costa et al., 2006; Bobb \& Wodniecka, 2013; Declerck \& Philipp, 2015a), while switch cost asymmetry is characteristic for unbalanced bilinguals, or second language learners, as switching back into the more dominant language incurs higher costs (Costa et al., 2006; Meuter \& Allport, 1999). Thus, our results confirm that switch cost asymmetry is related to differences in proficiency between varieties. Note that no switch cost asymmetry was found for passive bidialectals who reported having high familiarity with the dialect in comprehension but engaged in limited production in their every-day communication. This finding suggests that lexical entries are accessible based just on sufficient exposure to them in comprehension, in line with models of bilingual lexical representation that propose shared representations for comprehension and production (Grainger, Midgley, \& Holocomb, 2010).

\section{General Discussion}

The present study demonstrated that monolinguals who routinely use a dialect of their native language exhibit costs when prompted to switch between their two native linguistic varieties. It also demonstrated faster naming latencies for inter-dialectal cognates compared to non-cognates. These findings were remarkably robust across speakers using dialects of two different languages, German and English.

According to the Inhibitory Control framework (Abutalebi \& Green, 2008; Green, 1998), switch costs arise from the inhibition of entries tagged as belonging to the non-target language. According to the selective-activation framework (Poulisse, 1997; Costa \& Santesteban, 2004; Costa et al., 2006) the activation threshold for lexical entries of one language can be selectively lowered such as to allow languagespecific lexical selection. Both interpretations of the results lead to the conclusion that control mechanisms need to be adopted to achieve selective activation not just for different languages but also for different varieties such as dialects. Similarly, cognate facilitation arises either through activation of shared phonological representations via a word's translation equivalent (Costa, et al. 2000), or are the result of feedback from the phonological level to entries from both linguistic varieties on the lemma level (Bernolet, Hartsuiker, \& Pickering, 2012). Again, both interpretations are compatible with the view that there is concurrent activation of both linguistic varieties, which necessitates the initiation of control processes to ensure activation of the lexical entry in the target language. 
The findings that monodialectal speakers with recent limited dialect exposure exhibited asymmetric switch costs demonstrates that when lexical representations are sparse and not yet fully established, inhibitory control processes have to overcome greater inertia when switching back into the dominant variety (Declerck, Koch, \& Philipp, 2015; Green, 1998; Abutalebi \& Green, 2008). An alternative explanation for asymmetric switch costs does not rely on inhibition, but postulates that lexical entries in the more dominant variety, albeit activated faster, trigger a "double-checking procedure" to ensure correct production (Finkbeiner et al., 2006). While the goal of the present study was not to adjudicate between these different accounts, we note that our findings provide cross-linguistic evidence that bidialectal speakers in diglossic situations seem to rely on similar language control mechanisms as bilinguals.

\section{How different are monolinguals from bilinguals?}

To the extent that diglossia is widespread and many monolinguals switch flexibly between varieties of their language our results raise doubts regarding qualitative differences between monolinguals and bilinguals in terms of the architecture of lexical representations and the mechanisms of language control. For bilinguals, the need to exercise control to ensure selection of the target language and to prevent intrusions from the non-target language arises when task-schemas are in competition, as in single- and dual-language contexts, where usage is clearly separated by interlocutor or by social situation, but not necessarily in code-switching contexts where both languages can be used within a communicative episode or even a single utterance (Green \& Abutalebi, 2013). The situation of diglossia examined here is very similar to socially and situationally conditioned dual-language contexts experienced by many bilinguals. However, the establishment of dialect switch costs is only a first indicator that bidialectals may need to engage in flexible control of their linguistic varieties through inhibition or selective activation in similar ways as bilinguals do. Future studies will have to employ other experimental paradigms, such as picture-word interference or comprehension of ambiguous words, to corroborate that there is co-activation of multiple varieties in bidialectal word production.

The need to resolve competition from the non-target language is central to proposals that bilingualism may lead to a general advantage in executive functioning (Bialystok, Craik, Green \& Gollan, 2009; Salvatierra \& Rosselli, 2011; Schroeder \& Marian, 2012; Verreyt et al., 2016), and may even delay the onset of dementia in bilinguals relative to their monolingual counterparts (Alladi et al., 2013; Bialystok, Craik \& Friedman, 2007). This advantage is assumed to arise either because lexical access in bilinguals requires more frequent deployment of domain-general executive control processes compared to monolinguals (De Bruin, Roelofs, Dijkstra \& FitzPatrick, 2014), or because bilinguals transfer inhibitory control abilities from the linguistic to the non-linguistic domain (Bialystok et al., 2009). However, recent evidence has cast doubt on the existence of a bilingual advantage in non-linguistic cognitive control (Paap, Johnson \& Sawi, 2014, 2015; Paap, Myuz, Anders, Bockelman, Mikulinsky \& Sawi, 2016).

Our data suggest that one possible reason for failures to replicate a bilingual advantage may be that monolinguals themselves differ in the extent to which they have to exercise language control, based on the need to negotiate different varieties of their native language. In other words, if bidialectism in monolinguals remains undetected and unmeasured then this may be responsible for a lack of differences in executive control measures between monolinguals and bilinguals. Although this could 
be the case, we do not believe that an undetected bidialectism in monolinguals can fully account for such a lack of differences. Several studies have recently explored whether bidialectism incurs a cognitive control advantage similar to that found in bilinguals. These studies tested bidialectal speakers of Italian and Sardinian Italian (Lauchlan, Parisi \& Fadda, 2013), of Standard Greek and Cypriot Greek (Antoniou, Grohmann, Kambanaros \& Katsos, 2016) and of Standard Scottish English and Dundonian (Kirk, Fiala, Scott-Brown \& Kempe, 2014; Ross \& Melinger, 2016). The results of these studies are inconclusive: While comparisons of 32 Italian-Sardinian bidialectal children with 29 Italian monolingual children (Lauchlan et al., 2013), of 16 elderly English-Dundonian bidialectals with 16 elderly English-speaking monodialectals (Kirk et al., 2014), and of 48 English-Dundonian bidialectal children with 45 English-speaking monodialectal children (Ross \& Melinger, 2016) showed no evidence for a bidialectal advantage, neither in tests of cognitive ability nor in tests of cognitive control, the comparison of 64 Greek-Cypriot bidialectal children with 25 Greek monolingual children reported by Antoniou et al. (2016) supported a bidialectal advantage. However, that study did not control for confounds associated with differences in the specific educational environments associated with the different schools of the various groups. Overall, then, there is to date no compelling evidence that bidialectism leads to enhanced non-linguistic cognitive control. Thus, while bidialectals and bilinguals may indeed be similar in terms of how the lexicon accommodates different linguistic varieties (i.e. just as bilinguals, monolinguals may rely on control mechanisms in some situations such as switching between registers), this is unlikely to be the reason behind the reported failures to replicate a bilingual advantage.

\section{Should we assume tagging of lexical entries for linguistic variety?}

As discussed above, models of bilingual word production that attempt to explain language switching and cognate facilitation rely on the assumption that language-specificity of lexical entries is instantiated either through language tags (e.g. Green, 1998) or links to language nodes (Van Heuven, Dijkstra \& Grainger, 1998; Dijkstra \& van Heuven, 2002). Incorporating dialect-specific or register-specific marking of lexical entries in localist connectionist models as, for instance, the revised version of the Bilingual Interactive Activation model (Dijkstra \& van Heuven, 2002) would require instantiation of dialect- or register-specific nodes to account for the effects reported here. While such nodes remain a theoretical possibility it may be difficult to implement flexible use of socio-linguistic variation by instantiating multiple nodes for all the different dialects, accents, sociolects or registers that speakers may use in different situations.

Alternatively, distributed connectionist models like the Bilingual Language Interaction Network for Comprehension of Speech proposed by Shook and Marian (2013) postulates lexical representations that are created by interacting dynamic selforganizing maps on various levels of processing. This model assumes that language selection is guided by lingering localised activation patterns, which suppress, or compete with, access to more distant entries with lower activation levels belonging to the other language. The resulting difficulty in accessing the low-activation non-target language entries can account for language switch costs. Such models are, in principle, capable of accommodating representational separation of different linguistic varieties based on the same principles: self-organising maps of localised activation patterns for entries belonging to the same variety should emerge if the corresponding words share 
similar phonemic or phonological features or similar usage contexts. Such possibilities present interesting challenges for further model development.

Language-specific tags are also considered to be superfluous in frameworks according to which the linguistic variety a lexical entry belongs to could be specified at the conceptual level so that only target lexical entries are selectively activated in the first place (La Heij, 2005). Under this account, conceptual representations are rich and varied, and all the information that distinguishes variety-specific usage of words, e.g. whether to choose a formal or a colloquial form, is instantiated at the conceptual level so that once the appropriate conceptual constraints are specified, lexical selection becomes straightforward. In addition, it is conceivable that language and dialect switching costs arise to some extent from task-switching components that require selective attention to certain sub-lexical features of the words such as differences in morphological, segmental or sub-segmental features or in articulatory settings (Wilson \& Gick, 2014) associated with the different linguistic varieties. In this case, the locus of control would not be at the lexical level but at the level of assembling the appropriate phonological codes and/or articulatory routines (e.g., Declerck \& Philipp, 2015b; Philipp \& Koch, 2016). Thus, there may be considerable flexibility in terms of the levels of processing at which attention can be selectively allocated (cf. Declerck \& Philipp, 2015a; Gollan et al., 2014).

In general, examining selective activation of linguistic varieties such as dialects, accents, sociolects or registers will provide further insight into similarities and differences between language switching and general task switching mechanisms. Some previous research examining whether bilingual language control is a subsidiary of domain-general executive control has compared between-language switching with intra-language switching between nouns and verbs (Abutalebi, Annoni, Zimine, Pegna et al., 2008) or with non-linguistic switching between colour and shape (Calabria, Hernandez, Branzi \& Costa, 2012), and found that language control shows different patterns of switch costs and activates different brain areas. Other studies have shown links between performance in language switching and domain-general task switching (Prior \& Gollan, 2011; Weissberger et al., 2012, Declerck, Grainger, Koch \& Philipp, 2017) as well as overlap in the involved cortical pathways (DeBaene, Duyck, Brass \& Carreiras, 2015). It therefore remains a possibility that language control incorporates elements of task switching, e.g. switching between dimensions pertaining to conceptual or sub-lexical components of word production. To settle this question it will be instructive to conduct experiments examining switching between conceptual dimensions such as positive or negative affective connotations of words or between sub-lexical dimensions such as fully phonated vs. whispered speech. Comparing the patterns of switch costs in such tasks with those in language and dialect switching will provide insights into the contribution of other stimulus dimensions and task components to language switch tasks, and can help to ascertain to what extent the lexical level is the main locus of language control. While the outcomes of such experiments must await future research, the results of the present study highlight the flexibility in monolingual language control that is associated with the use of socio-linguistic variation. 
Notes:

${ }^{1}$ Note that there was no effect between switch costs and the DemTect scores indicating that cognitive decline was not responsible for increased switch costs in this sample.

${ }^{2}$ The same significant effects were obtained when self-reported percentage of daily usage of Dundonian was included as a covariate. 


\section{References:}

Abutalebi, J., \& Green, D. W. (2008). Control mechanisms in bilingual language production: Neural evidence from language switching studies. Language and Cognitive Processes, 23, 557-582.

Abutalebi, J., Annoni, J. M., Zimine, I., Pegna, A. J., Seghier, M. L., Lee-Jahnke, H., ... \& Khateb, A. (2008). Language control and lexical competition in bilinguals: an event-related fMRI study. Cerebral Cortex, 18(7), 1496-1505.

Alladi, S., Bak, T. H., Duggirala, V., Surampudi, B., Shailaja, M., Shukla, A. K., ... \& Kaul, S. (2013). Bilingualism delays age at onset of dementia, independent of education and immigration status. Neurology, 81(22), 1938-1944.

Antoniou, K., Grohmann, K. K., Kambanaros, M., \& Katsos, N. (2016). The effect of childhood bilectalism and multilingualism on executive control. Cognition, 149, 18-30.

Barr, D. J., Levy, R., Scheepers, C., \& Tily, H. J. (2013). Random effects structure for confirmatory hypothesis testing: Keep it maximal. Journal of Memory and Language, 68, 255-278.

Bates, D., Kliegl, R., Vasishth, S., \& Baayen, H. (2015). Parsimonious mixed models. arXiv preprint arXiv:1506.04967.

Bates, E., D’Amico, S., Jacobsen, T., Székely, A., Andonova, E., Devescovi, A., ... \& Wicha, N. (2003). Timed picture naming in seven languages. Psychonomic Bulletin \& Review, 10(2), 344-380.

Bernolet, S., Hartsuiker, R. J., \& Pickering, M. J. (2012). Effects of phonological feedback on the selection of syntax: Evidence from between-language syntactic priming. Bilingualism: Language and Cognition, 15(03), 503-516.

Bialystok, E., Craik, F. I., \& Freedman, M. (2007). Bilingualism as a protection against the onset of symptoms of dementia. Neuropsychologia, 45(2), 459464.

Bialystok, E., Craik, F. I., Green, D. W., \& Gollan, T. H. (2009). Bilingual minds. Psychological Science in the Public Interest, 10, 89-129.

Blumenfeld, H. K., \& Marian, V. (2011). Bilingualism influences inhibitory control in auditory comprehension. Cognition, 118(2), 245-257.

Bobb, S. C., \& Wodniecka, Z. (2013). Language switching in picture naming: What asymmetric switch costs (do not) tell us about inhibition in bilingual speech planning. Journal of Cognitive Psychology, 25, 568-585.

Calabria, M., Hernández, M., Branzi, F. M., \& Costa, A. (2012). Qualitative differences between bilingual language control and executive control: Evidence from task-switching. Frontiers in Psychology, 2, 399.

Christoffels, I. K., Firk, C., \& Schiller, N. O. (2007). Bilingual language control: An event-related brain potential study. Brain research, 1147, 192-208.

Costa, A., \& Caramazza, A. (1999). Is lexical selection in bilingual speech production language-specific? Further evidence from Spanish-English and EnglishSpanish bilinguals. Bilingualism: Language and Cognition, 2(03), 231-244.

Costa, A., \& Santesteban, M. (2004). Lexical access in bilingual speech production: Evidence from language switching in highly proficient bilinguals and L2 learners. Journal of Memory and Language, 50, 491-511.

Costa, A., Caramazza, A., \& Sebastian-Galles, N. (2000). The cognate facilitation effect: implications for models of lexical access. Journal of Experimental Psychology: Learning, Memory, and Cognition, 26, 1283-1296. 
Costa, A., Santesteban, M. \& Caño, A. (2005). On the facilitory effects of cognates words in bilingual speech production. Brain and Language, 94, 94-103.

Costa, A., Santesteban, M., \& Ivanova, I. (2006). How do highly proficient bilinguals control their lexicalisation process? Inhibitory and language-specific selection mechanisms are both functional. Journal of Experimental Psychology: Learning, Memory, and Cognition, 32, 1057-1074.

Costa, J. (2015). Can Schools Dispense with Standard Language? Some unintended consequences of introducing Scots in a Scottish primary school. Journal of Linguistic Anthropology, 25(1), 25-42.

De Baene, W., Duyck, W., Brass, M., \& Carreiras, M. (2015). Brain circuit for cognitive control is shared by task and language switching. Journal of Cognitive Neuroscience, 27(9), 1752-1765.

de Bruin, A., Roelofs, A., Dijkstra, T., \& FitzPatrick, I. (2014). Domain-general inhibition areas of the brain are involved in language switching: FMRI evidence from trilingual speakers. NeuroImage, 90, 348-359.

Declerck, M., \& Philipp, A. M. (2015a). A review of control processes and their locus in language switching. Psychonomic Bulletin \& Review, 22(6), 1630-1645.

Declerck, M., \& Philipp, A. M. (2015b). The unusual suspect: Influence of phonological overlap on language control. Bilingualism: Language and Cognition, 18, 726-736.

Declerck, M., Grainger, J., Koch, I., \& Philipp, A.M. (2017). Is language control just a form of executive control? Evidence for overlapping processes in language switching and task switching. Journal of Memory and Language, 95, 138-145.

Declerck, M., Koch, I., \& Philipp, A. M. (2012). Digits vs. Pictures: The influence of stimulus type on language switching. Bilingualism: Language and Cognition, 15, 896-904.

Declerck, M., Koch, I., \& Philipp, A. M. (2015). The Minimum Requirements of Language Control: Evidence from sequential predictability effects in language switching. Journal of Experimental Psychology: Learning, Memory, and Cognition, 41, 377-394.

Declerck, M., Thoma, A. M., Koch, I., \& Philipp, A. M. (2015). Highly proficient bilinguals implement inhibition: Evidence from n-2 language repetition costs. Journal of Experimental Psychology: Learning, Memory, and Cognition, 41(6), 1911.

Dijkstra, T., \& Van Heuven, W. J. (2002). The architecture of the bilingual word recognition system: From identification to decision. Bilingualism: Language and Cognition, 5(03), 175-197.

Dimitropoulou, M., Duñabeitia, J. A., \& Carreiras, M. (2011). Masked translation priming effects with low proficient bilinguals. Memory \& Cognition, 39(2), 260-275.

Feldhausen, Ingo (2010). Sentential Form and Prosodic Structure of Catalan. John Benjamins

Ferguson, C. A. (1959). Diglossia. Word, 15(2), 325-340.

Filippi, R., Karaminis, T., \& Thomas, M. S. C. (2014). Bilingual language switching in production: Empirical and computational studies. Bilingualism: Language and Cognition, 17, 294-315.

Finkbeiner, M., Almeida, J., Janssen, N., \& Caramazza, A. (2006). Lexical selection in bilingual speech production does not involve language suppression. Journal of Experimental Psychology: Learning, Memory, and Cognition, 32, 10751089. 
Foulkes, P., \& Hay, J. B. (2015). The emergence of sociophonetic structure. In B. MacWhinney \& W. O'Grady (Eds.), The Handbook of Language Emergence, (pp. 292-313). Oxford: Blackwell.

Gollan, T. H., \& Ferreira, V. S. (2009). Should I stay or should I switch? A costbenefit analysis of voluntary language switching in young and aging bilinguals. Journal of Experimental Psychology: Learning, Memory, and Cognition, 35(3), 640.

Gollan, T. H., Schotter, E. R., Gomez, J., Murillo, M., \& Rayner, K. (2014). Multiple levels of bilingual language control: Evidence from language intrusions in reading aloud. Psychological Science, 25(2), 585-595.

Grainger, J. Midgley, K. J., \& Holcomb, P. J. (2010). Re-thinking the bilingual interactive-activation model from a developmental perspective (BIA-d). In M. Kail and M. Hickman (Eds), Language Acquisition across linguistic and cognitive systems (pp. 267-284. Philadelphia: John Benjamins).

Green, D. W. (1998). Mental control of the bilingual lexico-semantic system. Bilingualism: Language and Cognition, 1(2), 67-81.

Green, D. W., \& Abutalebi, J. (2013). Language control in bilinguals: The adaptive control hypothesis. Journal of Cognitive Psychology, 25(5), 515-530.

Hermans, D., Bongaerts, T., De Boot, K. \& Schreuder, R. (1998). Producing words in a foreign language: Can speakers prevent interference from their first language? Bilingualism: Language and Cognition, 1(3), 213-229.

Johnston, Jr., P. A. (2007) Scottish English and Scots. In D. Britain (Ed.). Language in the British Isles. Cambridge University Press.

Kalbe, E., Kessler, J., Calabrese, P., Smith, R., Passmore, A. P., Brand, M. A., \& Bullock, R. (2004). DemTect: a new, sensitive cognitive screening test to support the diagnosis of mild cognitive impairment and early dementia. International Journal of Geriatric Psychiatry, 19(2), 136-143.

Kessler, J., Calabrese, P., Kalbe, E., \& Berger, F. (2000). DemTect: A new screening method to support diagnosis of dementia. Psycho, 26(6), 343-347.

Kiesel, A., Wendt, M., Jost, K., Steinhauser, M., Falkenstein, M., Philipp, A. M., \& Koch, I. (2010). Control and interference in task switching: A review. Psychological Bulletin, 136, 849-874.

Kirk, N. W., Fiala, L., Scott-Brown, K. C. \& Kempe, V. (2014). No evidence for reduced Simon cost in elderly bilinguals and bidialectals. Journal of Cognitive Psychology, 26(6), 640-648.

La Heij, W. (2005) Selection processes in monolingual and bilingual lexical access. In Kroll, J. and de Groot, A., editors, Handbook of bilingualism (pp. 289-307). Oxford: Oxford University Press.

Lauchlan, F., Parisi, M., \& Fadda, R. (2013). Bilingualism in Sardinia and Scotland: Exploring the cognitive benefits of speaking a 'minority'language. International Journal of Bilingualism, 17(1), 43-56.

Lewis, M. P., Gary F. Simons, G. F. \& Fennig, C. D. (eds.). 2016. Ethnologue: Languages of the World, Nineteenth edition. Dallas, Texas: SIL International. Online version: http://www.ethnologue.com.

Macizo, P., Bajo, T., \& Paolieri, D. (2012). Language switching and language competition. Second Language Research, 28, 131-149.

Marian, V., Blumenfeld, H. K., \& Kaushanskaya, M. (2007). The Language Experience and Proficiency Questionnaire (LEAP-Q): Assessing language profiles in bilinguals and multilinguals. Journal of Speech, Language, and Hearing Research, 50(4), 940-967. 
Meuter, R. F., \& Allport, A. (1999). Bilingual language switching in naming: Asymmetrical costs of language selection. Journal of Memory and Language, 40, 25-40.

Paap, K. R., Johnson, H. A., \& Sawi, O. (2014). Are bilingual advantages dependent upon specific tasks or specific bilingual experiences? Journal of Cognitive Psychology, 26, 615-639.

Paap, K. R., Johnson, H. A., \& Sawi, O. (2015). Bilingual advantages in executive functioning either do not exist or are restricted to very specific and undetermined circumstances. Cortex, 69, 265-278.

Paap, K. R., Myuz, H. A., Anders, R. T., Bockelman, M. F., Mikulinsky, R., \& Sawi, O. M. (2016). No compelling evidence for a bilingual advantage in switching or that frequent language switching reduces switch cost. Journal of Cognitive Psychology, 29(2), 89-112.

Philipp, A. M., \& Koch, I. (2016). Action speaks louder than words, even in speaking: The influence of (no) overt speech production on language-switch costs. In J. W. Schwieter (Ed.), Cognitive control and consequences in the multilingual mind (p. 127 - 144). John Benjamins Publishing.

Philipp, A. M., Gade, M., \& Koch, I. (2007). Inhibitory processes in language switching: Evidence from switching language-defined response sets. European Journal of Cognitive Psychology, 19, 395-416.

Poulisse, N., 1997. Language production in bilinguals. In: De Groot, A.M.B., Kroll, J.F. (Eds.), Tutorials in Bilingualism (pp. 201-224). Lawrence Erlbaum Associates, Mahwah, NJ.

Prior, A., \& Gollan, T. H. (2011). Good language-switchers are good task-switchers: Evidence from Spanish-English and Mandarin-English bilinguals. Journal of the International Neuropsychological Society: JINS, 17(4), 682.

Roelofs, A. (1992). A spreading-activation theory of lemma retrieval in speaking. Cognition, 42, 107-142.

Ross, J., \& Melinger, A. (2016). Bilingual advantage, bidialectal advantage or neither? Comparing performance across three tests of executive function in middle childhood. Developmental Science.

Salvatierra, J. L., \& Rosselli, M. (2011). The effect of bilingualism and age on inhibitory control. International Journal of Bilingualism, 15, 26-37.

Schroeder, S. R., \& Marian, V. (2012). A bilingual advantage for episodic memory in older adults. Journal of Cognitive Psychology, 24(5), 591-601.

Schwieter, J. W., \& Sunderman, G. (2008). Language switching in bilingual speech production: In search of the language-specific selection mechanism. The Mental Lexicon, 3, 214-238.

Scottish Government. (2010). Public attitudes towards the Scots language. Retrieved from: http://www.gov.scot/Publications/2010/01/06105123/0

Shook, A., \& Marian, V. (2013). The bilingual language interaction network for comprehension of speech. Bilingualism: Language and Cognition, 16(2), 304324.

Snodgrass, J. G., \& Vanderwart, M. (1980). A standardised set of 260 pictures: Norms for name agreement, image agreement, familiarity, and visual complexity. Journal of Experimental Psychology: Human Learning and Memory, 6, 174-215.

Stuart-Smith, J. (2004). Scottish English: Phonology. A Handbook of Varieties of English, 1, 47-67. 
Van Heuven, W. J. B., Dijkstra, T., \& Grainger, J. (1998). Orthographic neighborhood effects in bilingual word recognition. Journal of Memory and Language, 39, 458-483.

Verhoef, K., Roelofs, A., \& Chwilla, D. J. (2009). Role of inhibition in language switching: Evidence from event-related brain potentials in overt picture naming. Cognition, 110, 84-99.

Verreyt, N., Woumans, E., Vandelanotte, D., Szmalec, A., \& Duyck, W. (2016). The influence of language-switching experience on the bilingual executive control advantage. Bilingualism: Language and Cognition, 19(01), 181-190.

Weissberger, G. H., Wierenga, C. E., Bondi, M. W., \& Gollan, T. H. (2012). Partially overlapping mechanisms of language and task control in young and older bilinguals. Psychology and Aging, 27(4), 959.

Wilson, I., \& Gick, B. (2014). Bilinguals use language-specific articulatory settings. Journal of Speech, Language, and Hearing Research, 57(2), 361-373. 
Appendix 1: Experimental materials:

List of Standard German and Öcher Platt words used in Experiment 1:

\begin{tabular}{llllll}
\hline Cognates & & & & Non-Cognates \\
\hline Standard & Platt & gloss & Standard & Platt & gloss \\
\hline Banane & Banan & banana & Auto & Wajjel & car \\
Vogel & Vouel & bird & Gabel & Ferschett & fork \\
Junge & Jong & boy & Ziege & Jeäß & goat \\
Frosch & Freusch & frog & Harfe & Leire & harp \\
Schlüssel & Schlössel & key & Hose & Bogs & trousers \\
Messer & Mezz & knife & Pfirsich & Plüschprümm & peach \\
Baumstamm & Boumstamm & tree trunk & Kartoffel & Eädappel & potato \\
Eimer & Emmer & bucket & Regenschirm & Pärreplü & umbrella \\
Schnecke & Schleck & snail & Rauch & Schwaam & smoke \\
\hline
\end{tabular}

List of Standard English and Dundonian words used in Experiment 2:

\begin{tabular}{llll}
\hline Cognates & & Non-Cognates & \\
\hline Standard & Dundonian & Standard & Dundonian \\
(Anglo/Scottish) English & Scots & (Anglo/Scottish) English & Scots \\
\hline eyes & ezz & armpit & oxter \\
farmer & fermer & boy & laddie \\
garden & gairden & children & bairns \\
glasses & glesses & ears & lugs \\
heart & hert & girl & lassie \\
house & hoose & hill & brae \\
mouse & moose & potato & tattie \\
sausages & sassages & slippers & baffies \\
screwdriver & screwdrevver & turnips & neeps \\
\hline
\end{tabular}


Appendix 2: Dialect Usage portion of the Background Questionnaire. Reverse-coded statements are marked with ' $\mathrm{R}$ '.

We are interested in whether you ever communicate using a specific Scots dialect (such as Dundonian). For example, using words like "doon" instead of "down", "ken" instead of "know", "braw" instead of "good" or describing the weather as "dreich".

Which is your native variety (the one you spoke first)?

Standard Scottish English [ ]

Dundonian [ ]

Both [ ]

If you speak a different Scots dialect (other than Dundonian) please name it here:

What percentage of the time do you use Standard Scottish English (SSE) and Dundonian? Please mark an X where you think you fit on the scale below:

I use SSE 100\%

I switch between

of the time SSE and Dundonian

I use Dundonian

(0\% Dundonian and use each around $100 \%$ of the time $50 \%$ of the time

(0\% SSE)

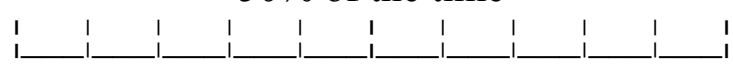

On a scale of $1-7$ please rate your ability to UNDERSTAND what a Dundonian speaker is saying. (please circle)

$\begin{array}{ccccccc}1 & 2 & 3 & 4 & 5 & 6 & 7 \\ \text { can't understand } & & & & & & \text { completely understand }\end{array}$

Please rate, by placing an $\mathbf{x}$ under the appropriate number, how much you agree with the following statements.

$$
1=\text { completely disagree } \quad 4=\text { not sure } \quad 7=\text { completely agree }
$$

\begin{tabular}{|l|l|l|l|l|l|l|l|}
\hline & 1 & 2 & 3 & 4 & 5 & 6 & 7 \\
\hline $\begin{array}{l}\text { Parents should encourage their children to use } \\
\text { Dundonian. }\end{array}$ & & & & & & \\
\hline $\begin{array}{l}\text { I think speaking Dundonian may be useful in the } \\
\text { workplace. }\end{array}$ & & & & & & \\
\hline $\begin{array}{l}\text { R: Parents should discourage their children from using } \\
\text { Dundonian as it is not the proper way to speak. }\end{array}$ & & & & & \\
\hline $\begin{array}{l}\text { People should be encouraged to use their local dialect as } \\
\text { much as possible. }\end{array}$ & & & & & & \\
\hline $\begin{array}{l}\text { R: Standard Scottish English is the correct way for } \\
\text { people in Scotland to speak. }\end{array}$ & & & & & & & \\
\hline R: I would correct my child if they said "toon" instead & & & & & & & \\
\hline
\end{tabular}


of "town" or "dinna" instead of "don't".

R: I would correct my child if they used words like "dreich" instead of "overcast/rainy" or "scunnered" instead of "disgusted/sick of".

People should be encouraged to use Dundonian as a way of expressing their local identity. 
Appendix 3: Means (and standard deviations in parentheses) for naming latencies (top line) and percent of errors (bottom line), computed with participants as random effects.

\begin{tabular}{|c|c|c|c|c|}
\hline & $\begin{array}{l}\text { Standard } \\
\text { cognate }\end{array}$ & non-cognate & $\begin{array}{l}\text { Dundoniar } \\
\text { cognate }\end{array}$ & non-cognate \\
\hline \multicolumn{5}{|c|}{ active bidialectals } \\
\hline \multirow[t]{2}{*}{ non-switch } & 793 (194) & $983(223)$ & $797(204)$ & $939(212)$ \\
\hline & $1.6(2.6)$ & $3.9(6.2)$ & $3.8(4.1)$ & $3.4(4.0$ \\
\hline \multirow[t]{2}{*}{ switch } & $840(183)$ & $1070(266)$ & $834(210)$ & $1037(269)$ \\
\hline & $3.1(4.8)$ & $3.8(5.1)$ & $3.3(3.5)$ & $4.5(4.9)$ \\
\hline \multicolumn{5}{|c|}{ passive bidialectals } \\
\hline \multirow[t]{2}{*}{ non-switch } & $835(140)$ & $1060(163)$ & $874(158)$ & $984(145)$ \\
\hline & $1.3(2.1)$ & $3.5(3.9)$ & $3.1(4.9)$ & $2.6(4.0)$ \\
\hline \multirow[t]{2}{*}{ switch } & 895 (176) & 1148 (209) & $910(167)$ & $1108(198)$ \\
\hline & $0.7(2.1)$ & $4.5(4.4)$ & $1.9(3.3)$ & $4.0(5.5)$ \\
\hline \multicolumn{5}{|c|}{ monodialectals } \\
\hline \multirow[t]{2}{*}{ non-switch } & 858 (118) & $1026(156)$ & 927 (137) & $1026(179)$ \\
\hline & $3.1(3.3)$ & $5.1(6.4)$ & $3.1(5.5)$ & $3.7(3.3)$ \\
\hline \multirow[t]{2}{*}{ switch } & 994 (178) & 1174 (203) & $989(185)$ & $1123(257)$ \\
\hline & $3.5(5.1)$ & $9.1(6.5)$ & $6.7(3.3)$ & $5.5(6.2)$ \\
\hline
\end{tabular}


Appendix 4: Analysis of Experiment 2: Non-standardised coefficients, $t$ and $p$-values for significant effects in mixed-effect models for naming latencies with fixed effects of Linguistic Variety (Standard English vs. Dundonian), Cognate Status (cognates vs. non-cognates) and Trial Type (switch vs. non-switch) and crossed random effects of participants and images, including slopes of the fixed effects in the random effect structure [R-command: $\operatorname{lmer}($ ReactionTime $\sim$ LingVariety * CognateStatus * TrialType * PassiveBidial * Monodial $+(1+$ LingVariety + CognateStatus + TrialTypec $\mid$ Subject $)+(1+$ TrialType + PassiveBidial + Monodial | Image $))]$. The top model includes Dialect Group, effect-coded for passive bidialectals and monodialectals; the three bottom models present effects for each dialect group separately. Asterisks mark each effect for ease of reference using $*$ for $\mathrm{p}<.05, * *$ for $\mathrm{p}<.01$, and $* * *$ for $\mathrm{p}<001$.

\begin{tabular}{lrrr}
\hline & $\beta$ & $\mathrm{t}$ & $\mathrm{p}$ \\
\hline (Intercept) & 963.09 & 35.65 & $<0.001$ \\
LingVariety & 4.58 & 0.89 & 0.38 \\
CognateStatus*** & 82.58 & 7.80 & $<0.001$ \\
TrialType*** & 41.54 & 7.47 & $<0.001$ \\
PassiveBidialectals & 62.55 & 1.00 & 0.32 \\
Monodialectals & 106.75 & 1.69 & 0.10 \\
LingVariety x CognateStatus*** & 15.45 & 7.05 & $<0.001$ \\
LingVariety x TrialType* & 4.81 & 2.20 & 0.03 \\
CognateStatus x TrialType & 5.80 & 1.42 & 0.17 \\
LingVariety x PassiveBidialectals & -4.87 & -0.39 & 0.70 \\
LingVariety x Monodialectals & -13.29 & -1.05 & 0.30 \\
CognateStatus x PassiveBidialectals & -3.48 & -0.24 & 0.82 \\
CognateStatus x Monodialectals & -19.90 & -1.21 & 0.23 \\
TrialType x PassiveBidialectals & 4.70 & 0.44 & 0.66 \\
TrialType x Monodialectals* & 25.37 & 2.37 & 0.02 \\
LingVariety x CognateStatus x TrialType & -4.26 & -1.94 & 0.05 \\
LingVariety x CognateStatus x PassiveBidialectals & 9.57 & 1.80 & 0.07 \\
LingVariety x CognateStatus x Monodialectals & 6.14 & 1.14 & 0.26 \\
LingVariety x TrialType x PassiveBidialectals & -5.69 & -1.07 & 0.29 \\
LingVariety x TrialType x Monodialectals* & 14.52 & 2.69 & 0.01 \\
CognateStatus x TrialType x PassiveBidialectals & 1.67 & 0.31 & 0.75 \\
CognateStatus x TrialType x Monodialectals & -1.88 & -0.35 & 0.73 \\
LingVar x CognateStatus x TrialType x PassBidialect & -8.02 & -1.50 & 0.13 \\
LingVar x CognateStatus x TrialType x Monodialect & -3.10 & -0.57 & 0.57 \\
& & & \\
Intercept*** & & & \\
LinguisticVariety & 908.29 & 17.06 & $<0.001$ \\
CognateStatus*** & 10.53 & 2.04 & 0.059 \\
TrialType*** & 91.80 & 5.62 & $<0.001$ \\
LinguisticVariety x CognateStatus* & 32.75 & 5.86 & $<0.001$ \\
LinguisticVariety x TrialType & 10.00 & 2.61 & 0.013 \\
CognateStatus x TrialType & 1.75 & 0.28 & 0.780 \\
LinguisticVariety x CognateStatus x TrialType & 6.93 & 1.50 & 0.149 \\
& -0.48 & -0.11 & 0.912
\end{tabular}

Passive bidialectals 
Intercept ${ }^{* * *}$

LinguisticVariety

CognateStatus***

TrialType***

LinguisticVariety x CognateStatus***

LinguisticVariety $x$ TrialType

CognateStatus x TrialType

LinguisticVariety x CognateStatus x TrialType

Monodialectals

Intercept ${ }^{* * *}$

LinguisticVariety

CognateStatus***

TrialType***

LinguisticVariety x CognateStatus***

LinguisticVariety $\mathrm{x}$ TrialType $* * *$

CognateStatus $x$ TrialType

LinguisticVariety x CognateStatus x TrialType

$\begin{array}{rrr}969.88 & 24.04 & <0.001 \\ 5.03 & 0.44 & 0.665 \\ 88.00 & 7.15 & <0.001 \\ 36.20 & 5.02 & <0.001 \\ 19.54 & 3.16 & 0.005 \\ -3.65 & -0.90 & 0.375 \\ 7.82 & 1.50 & 0.152 \\ -8.75 & -1.96 & 0.066 \mathrm{~V}\end{array}$

\begin{tabular}{rrr}
1014.50 & 24.37 & $<0.001$ \\
-2.62 & -0.28 & 0.780 \\
71.52 & 5.28 & $<0.001$ \\
57.52 & 5.63 & $<0.001$ \\
16.70 & 2.49 & 0.023 \\
16.35 & 3.37 & 0.002 \\
4.94 & 1.01 & 0.320 \\
-3.85 & -0.79 & 0.437 \\
\hline
\end{tabular}

